\title{
Alveolar Surfactant
}

\author{
John L. Harwood, Llinos W. Morgan, and Tanya Greatrex
}

$\begin{array}{lll}\text { The Nature of Alveolar Surfactant } & \ldots & 44 \\ \text { Alveolar Lipids . . . . . . . . . . . . } & 45 \\ \text { Why So Much } & 44 \\ \text { Dipalmitoylphosphatidylcholine? . . . } & 47 \\ \text { The Biosynthesis of Surfactant Lipids . . } & 48 \\ \text { Remodeling of Newly Formed } & & \\ \text { Phospholipids . . . . . . . . . . . } & 50 \\ \text { Alveolar Surfactant Contains Special } & & \\ \text { Proteins . . . . . . . . . . . . . } & 51\end{array}$
The Different Structures of Surfactant-

Associated Proteins . . . . . . . . . 51

Possible Functions of Surfactant-

Associated Proteins ... . . . . . 53

Secretion and Turnover of Surfactant . . 54

Respiratory Distress and Alveolar

Surfactant ........... 56

Other Diseases That May Involve

Surfactant ........... 58

\section{The Nature of Alveolar Surfactant}

Alveolar surfactant is a remarkable and highly active surface material composed of lipids and proteins that are present in the fluid lining the alveolar surface of the lungs (Griese, 1999). It has several distinct features, and is carefully regulated under a range of normal physiological conditions throughout life. Indeed, the regulation of alveolar surfactant composition and its secretory rate into the alveoli is itself a superb example of metabolic regulation in practice.

Alveolar surfactant occurs in two major pools: extracellular and intracellular. By washing (lavaging) lungs it is possible to obtain preparations that contain the extracellular surfactant, which has been secreted into the alveoli and which, therefore, represents the functional material. Such material, however, will be contaminated by compounds from the upper airways, and it is difficult to obtain complete recovery of the total extracellular surfactant. Nevertheless, alveolar surfactant purified from lung lavages has a consistent composition from a large number of animal species. Moreover, the purified surfactant has the required physical properties expected of a material that produces a stable film of low surface tension that prevents alveolar collapse at end expiration in vivo. This is its biophysical function. Its nonbiophysical function is the protection of the lungs from injuries and infections caused by inhaled particles and microorganisms (Giese, 1999; Jobe and Ikegami, 2001).

Intracellular alveolar surfactant is present in the so-called lamellar bodies of the alveolar type-II epithelial cells. It has not been studied as much as the extracellular material, but, even so, material from quite a number of animal species has been exam- 
TABLE 3.1. Basic composition of alveolar surfactant.

\begin{tabular}{lcl}
\hline & wt. $\%$ & \multicolumn{1}{c}{ Types } \\
\hline Protein & 10 & $\begin{array}{l}\text { Specific surfactant proteins } \\
\text { SP-A, SP-B, SP-C, SP-D. }\end{array}$ \\
Lipid & 90 & $\begin{array}{l}\text { About } 90 \% \text { phospholipid, of which DPPC makes up half. } \\
\text { Phosphatidylglycerol noticeably present at about } 10 \% \text { of phospholipids. }\end{array}$
\end{tabular}

ined. In general terms, it has a composition similar to the extracellular material that would be expected because it is the physiological precursor.

Alveolar surfactant is a lipid-rich lipoprotein mixture. It contains approximately $90 \%$ lipid, $10 \%$ protein, and small amounts of carbohydrate (as glycosyl groups on proteins) (Table 3.1). The lipid composition is dominated by phosphatidylcholine (PC), particularly its dipalmitoyl-molecular species (Fig. 3.1). The presence of significant amounts of phosphatidylglycerol is another interesting feature because it is not normally found in any more than trace amounts in mammalian tissues. The synthesis, secretion, and metabolism of dipalmitoylphosphatidylcholine (DPPC) and other surfactant lipids has been the subject of a number of comprehensive reviews (Harwood and Richards, 1985; Harwood, 1987; Post and van Golde, 1988; van Golde et al., 1988; Ballard, 1989; Batenberg, et al., 1990; Bourbon, 1991; Johansson and Curstedt, 1997). Although surfactant preparations purified from lung washings typically contain quite a number of proteins, most of these (e.g., albumin) appear to have derived from the plasma; however, several surfactant specific proteins (i.e., SP-A, SP-B, SP-C and SP-D) have been found. These are closely associated with surfactant lipids and appear to contribute to the overall surfactant properties. Indeed, studies suggest that the surfactant-associated proteins may play other important roles in surfactant biology. Several reviews can also be consulted for information about these proteins (Whitsett et al., 1985; BAL Coop. Group Steering Committee, 1990; Weaver and Whitsett, 1991; Wright, 1997; Haagsman and Diemel, 2001).

\section{Alveolar Lipids}

Most lipid extracts from mammalian tissues contain a range of compounds including neutral lipids, cholesterol, phospholipids, and sphingolipids. For alveolar surfactant the pattern is unusually simple (Table 3.2). Cholesterol is really the only important neutral

FIGURE 3.1. Dipalmitoylphosphatidylcholine: the major lipid component of alveolar surfactant.

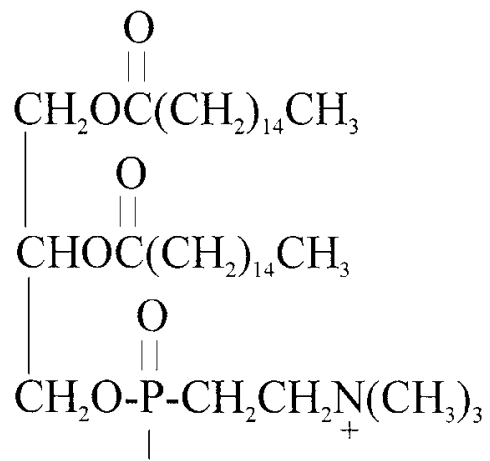


TABLE 3.2. The lipid composition of some isolated alveolar surfactants.

\begin{tabular}{lcccc}
\hline & Dog & Human & Rat & Rabbit \\
\hline Neutral lipid & 13 & 10 & 11 & 14 \\
Triacylglycerol & 14 & 26 & 25 & 20 \\
Cholesterol & 86 & 71 & 57 & 70 \\
Others & - & 23 & 18 & 10 \\
Phospholipids & 87 & 90 & 89 & 86 \\
Phosphatidylcholine & 76 & 73 & 80 & 76 \\
Phosphatidylethanolamine & 6 & 3 & 4 & 5 \\
Phosphatidylglycerol & 7 & 12 & 9 & 8 \\
Phosphatidylinositol & 4 & 6 & 3 & 4 \\
Others & 7 & 6 & 4 & 7 \\
\hline
\end{tabular}

The neutral lipid and phospholipid values are expressed as \% of total lipid. The individual neutral lipids or phospholipids are shown as a $\%$ of these two classes.

lipid, but its level is rather insignificant compared with its normal amounts in, say, plasma membranes.

PC is by far the major phospholipid in surfactant. In most tissue extracts this phospholipid class would be expected to be present at up to $50 \%$ of the total, but it represents about three-quarters of all phospholipids in alveolar surfactant. The second-most abundant phospholipid is usually phosphatidylglycerol at about $10 \%$. This is very unusual because phosphatidylglycerol is uncommon in animals. Because of its level in surfactant, phosphatidylglycerol has been suggested to be a "marker" component and to play some vital functional role. Both of these properties, however, are negated by its low levels in cat surfactants and various other air-breathing animals such as the chicken. In such cases, phosphatidylglycerol appears to be replaced by another negatively charged phospholipid, phosphatidylinositol. The latter is another significant component of surfactant (Table 3.2) and is formed by a biosynthetic route common to phosphatidylglycerol.

Other phospholipids are insignificant. Phosphatidylethanolamine, the second most prevalent membrane phospholipid in animals is only present in minor amounts, whereas sphingomyelin and phosphatidylserine are trace constituents. Diphosphatidylglycerol (cardiolipin), which can be regarded as a mitochondrial marker, is absent. One trace constituent that has been found in alveolar surfactant preparations is platelet-activating factor (PAF; 1-acyl, 2-acetylphosphatidylcholine) whose presence explains the plateletactivating properties of such isolates, especially from the fetal lung.

Each phospholipid class contains a variety of molecular species [i.e., different combinations of acyl (or alkyl) chains at the $s n-1$ and $s n-2$ positions of the glycerol backbone]. To a student it may seem tedious that such complications are mentioned. In terms of function, however, the nature of the exact molecular species is very important indeed (see later).

The fatty acid composition of phosphatidylcholines from different alveolar surfactants is shown in Table 3.3. It will be seen, clearly, that palmitate is the dominant fatty acid constituent. If you bear in mind that two acyl chains are present in each phosphatidylcholine molecule, more than half of the individual species are dipalmitoyl. In fact, together with the other saturated acids, myristate and stearate, disaturated phosphatidylcholines make up $60-80 \%$ of the total, compared with only $4 \%$ in the liver. There are good reasons for this when one considers the constant exposure of the surface layer of phospholipid in the alveoli to air and the tendency for unsaturated acyl 
TABLE 3.3. Fatty acid composition of phosphatidylcholine fractions from some isolated alveolar surfactants.

\begin{tabular}{lccccccc}
\hline & \multicolumn{7}{c}{ Composition (\% total fatty acids) } \\
\cline { 2 - 8 } Animal & $14: 0$ & $16: 0$ & $16: 1$ & $18: 0$ & $18: 1$ & $18: 2$ & Others \\
\hline Dog & 5 & 67 & 4 & 7 & 10 & 1 & 6 \\
Human & 3 & 81 & 6 & 3 & 5 & 2 & Traces \\
Pig & 5 & 73 & 6 & 3 & 10 & 1 & 2 \\
Rat & 2 & 83 & 1 & 2 & 7 & 2 & 3 \\
Rabbit & 3 & 73 & 6 & 3 & 13 & 2 & Traces \\
\hline
\end{tabular}

Fatty acids are abbreviated with the first figure indicating the number of carbons and the number after the colon showing the number of double bonds. 14:0 = myristate; $16: 0=$ palmitate; $16: 1=$ hexadecanoate (mainly palmitoleate) $; 18: 0=$ stearate; $18: 1=$ octadecenoate (mainly oleate) and $18: 2$ is mainly linoleate.

chains to oxidize. The other phospholipid classes are also quite saturated, although less so than phosphatidylcholine.

Other phospholipid variants (e.g., plasmalogens) have been reported, but they are quantitatively unimportant.

\section{Why So Much Dipalmitoylphosphatidylcholine?}

It is generally thought that the main functional agent of alveolar surfactant is DPPC. Although the biophysical basis of surfactant activity and the precise physiological mechanims of its action are still controversial (Bangham, 1991), a good correlation between the interfacial properties of surfactant and its physiological efficacy seems to exist. DPPC could be considered to be an ideal lipid to form a stable surface layer at the air-liquid interface in the alveolus. It is amphipathic, so it will naturally form a monolayer with the fatty acyl chains projecting into the air, whereas the polar phosphocholine moiety interacts with the aqueous phase. The negative charge on the phosphate group is balanced by a positive charge on the choline, thus rendering the molecule zwitterionic. Moreover, the dimensions of the polar part of the phospholipid are equal to those of the nonpolar (acyl) part that means that DPPC is cylindrical in shape and can easily pack into a monolayer. In addition, there is good hydrophobic bonding between the two palmitoyl residues.

The surface behavior of phosphatidylcholines, lung surfactant, and other derivatives can be measured by using a Wilhelmy balance and a hydrophobic Langmuir trough with cyclic compression-expansion (Gaines, 1966) or by the pulsating bubble technique (Enhorning, 1977). It has been suggested that it is important for phosphatidylcholines with a transition temperature (Tc; the temperature at which the acyl chains change from the gel to the liquid phase) greater than body temperature to be present for a stable, low surface tension film to be formed (Goerke and Gonzales, 1981). When mixtures of PC species were subjected to dynamic compression, the more fluid, unsaturated components were gradually squeezed out to leave a monolayer enriched in DPPC (Hawco et al., 1981). Indeed, the rate of "squeeze-out" and, hence, enrichment of the monolayer depends on the rate of compression-expansion. In fact, there is also a minimum proportion of DPPC that is needed to produce surface tensions low enough for lung stability. This is thought to be around 50\% (Bourbon, 1991), which is a concentration easily met by natural alveolar surfactant. The unsaturated phospholipid con- 
TABLE 3.4. Contribution of different surfactant components for lipid phase formation.

\begin{tabular}{lll}
\hline Component & \multicolumn{1}{c}{ Property } & \multicolumn{1}{c}{ Function } \\
\hline DPPC-enriched monolayer & Rigid chains (below $\mathrm{T}_{\mathrm{c}}$ ) & $\begin{array}{l}\text { Provides very low surface tension } \\
\text { Stability at low surface tension }\end{array}$ \\
Unsaturated lipids & Acyl chains fluid & $\begin{array}{l}\text { Monolayer spreading, tubular } \\
\text { myelin formation }\end{array}$ \\
$\begin{array}{l}\text { Acidic lipids }+\mathrm{Ca}^{++}+ \\
\text {apoprotein }\end{array}$ & $\begin{array}{l}\text { Bilayer inhomogeneities } \\
\text { (nonbilayer states) }\end{array}$ & $\begin{array}{l}\text { Monolayer spreading, tubular } \\
\text { myelin formation }\end{array}$ \\
$\begin{array}{l}\text { High DPPC content (other } \\
\text { lipid mixtures) }\end{array}$ & $\begin{array}{l}\text { Monolayer inhomogeneities } \\
\text { Transient lipid clusters }\end{array}$ & Selective exclusion \\
\hline
\end{tabular}

Source: After Harwood and Richards, 1985, with permission.

stituents are thought to be needed in order to aid the initial adsorption and spreading of the surface film (King and Clements, 1972). Phosphatidylglycerol and unsaturated PCs would have this function in vivo. In most situations, phosphatidylinositol seems able to substitute for phosphatidylglycerol, although there are occasional situations where phosphatidylglycerol appears to be definitely superior. One such example is around birth, where newborns suffering from transient tachypnea (a mild and transient respiratory difficulty) were shown to have a specific deficiency in phosphatidylglycerol (Bourbon et al., 1990). Moreover, whatever the putative role of phosphatidylglycerol, its presence in surfactant (or amniotic fluid) is a valuable index of fetal lung maturity and is indicative that all the functional elements of surfactant are present. Thus, it is almost unknown to find respiratory distress of the newborn when surfactant phosphatidylglycerol is abundant.

The probable contributions of different lipids to surfactant function are summarized in Table 3.4.

\section{The Biosynthesis of Surfactant Lipids}

Phosphatidylcholine can be synthesized by several different routes, but the CDPcholine pathway is the main route in mammalian tissues (and the lung is no exception). The latter consists of three steps (Fig. 3.2). Of these, the final step is freely reversible and, therefore, unimportant in regulating the overall speed of phosphatidylcholine formation. The first step, which is catalyzed by choline kinase, usually has high rates and is not considered to be rate-limiting, whereas the cytidylyltransferase is. The evidence that cholinephosphate cytidylyltransferase is rate-limiting comes from several sources (Table 3.5).

Following results with the liver, where the regulation of cholinephosphate cytidylyltransferase through subcellular translocation has been well studied, the enzyme from the lung has been examined. When the enzyme was purified (Feldman et al., 1978) two forms of the cytidylyltransferase were found. The higher molecular weight form (5-50 $\left.\times 10^{6}\right)$ was more active than the other $(190,000)$, and its activity was increased by preincubation with phosphatidylglycerol. Moreover, phosphatidylglycerol also shifted the apparent subcellular distribution so that a greater proportion was found in the microsomal fraction and less in the cytosol (Stern et al., 1976). This would all fit with the better-demonstrated liver situation; however, the role of translocation in the regulation of cholinephosphate cytidylyltransferase (CPCT) is still unresolved and some 
Glycerol 3-phosphate

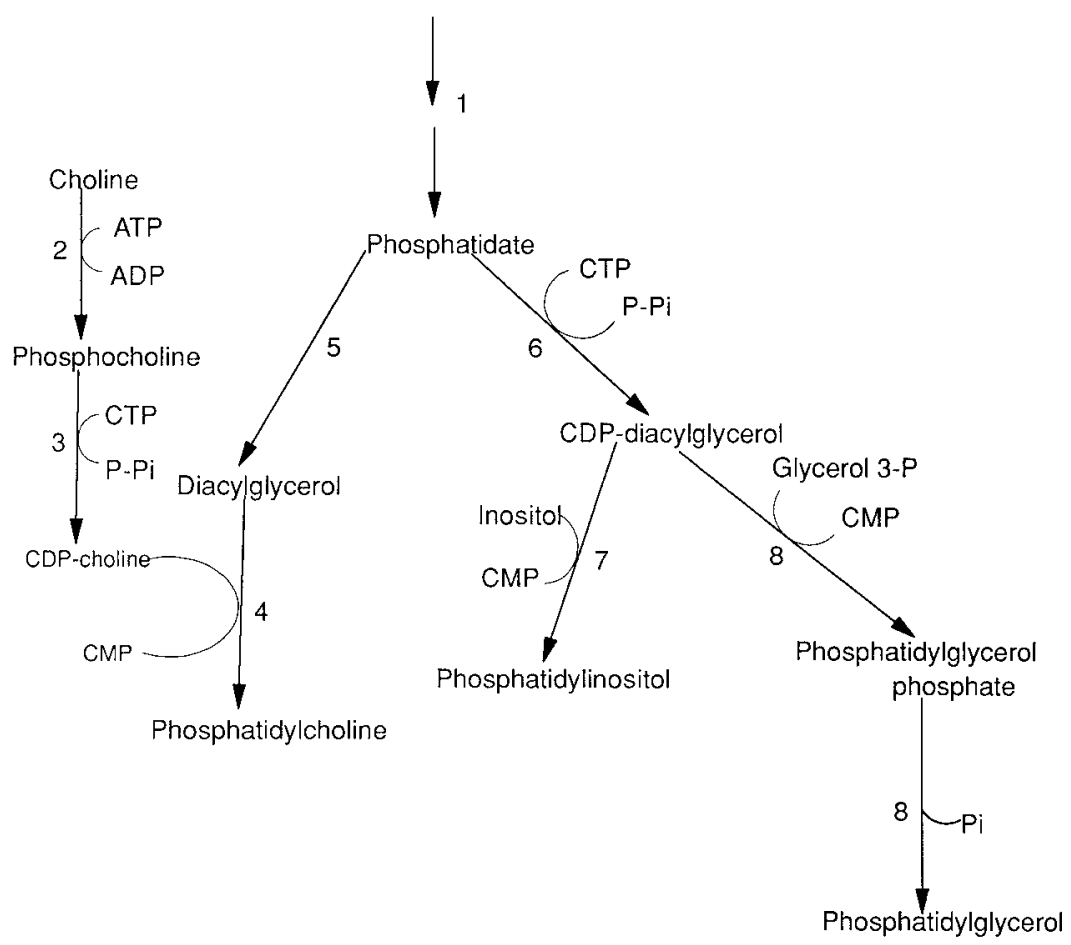

FIGURE 3.2. Biosynthesis of the main surfactant lipids.

workers believe that activation of pre-existing microsomal enzyme is more important, especially in connection with hormone-stimulated phosphatidylcholine synthesis (Post, 1987). Other studies have clarified the relationships between different forms of the enzyme and its subcellular location (Feldman et al., 1990). The microsomal form has the greatest activity. Moreover, the cytosolic form is believed to be translocated to the endoplasmic reticulum (Kalmar et al., 1994). Thus, CPCT is stimulated by some phospholipids modulated by phosphorylation, and its activity is increased by translocation from cytosol to endoplasmic reticulum.

Instead of phosphatidate being used as a source of diacylglycerol for zwitterionic phospholipids, it can itself be subject to a cytidylyltransferase reaction and converted

TABLE 3.5. Evidence that cholinephosphate cytidylyltransferase (CPCT) is rate-limiting for phosphatidylcholine formation.

- CPCT activity increases coincidently with phosphatidylcholine formation in developing lungs.

- CDP-choline is the smallest pool of the various choline intermediates.

- CPCT activity measured in vitro is usually lower than either choline kinase or phosphocholine transferase.

- Hormones that increase surfactant production also stimulate CPCT activity.

- The antagonistic actions of insulin and glucocorticoids on developing lung seem to be expressed at the level of CPCT. 
to CDP-diacylglycerol (see Fig. 3.2). Because the intracellular concentration of this cytidylyltransferase is low, its activity may limit the overall rate of acidic phospholipid synthesis. Once CDP-diacylglycerol has been formed it is used as substrate by phosphatidylinositol synthase. Only myo-inositol (of the 16 possible isomers of inositol) is used for lipid formation. The activity of the lung enzyme rises gradually during the perinatal period to reach its highest level in the adult (Harwood, 1987). In contrast, the glycerolphosphate phosphatidyltransferase that catalyses the first of the two reactions to form phosphatidylglycerol showed a steeper rise in activity immediately before birth, just when this phospholipid became a significant component of surfactant.

Thus, the ratio of the acidic lipids, phosphatidylinositol and phosphatidylglycerol, changes markedly just before term. This alteration is produced mainly through a sudden increase in the production of phosphatidylglycerol. The cause of this change in metabolism has been investigated and two possible causative factors: CMP and inositol. Serum inositol levels decline just before birth, and such a change might reduce phosphatidylinositol synthesis (Bleasdale and Johnson, 1985). Doubts about this simple idea, however, come from the observation that inositol levels in lung tissue in fetal animals were the same as in adults (Bleasdale et al., 1982). As an alternative it has been shown that CMP stimulates the reverse reaction of phosphatidylinositol synthase to increase CDP-diacylglycerol levels. CMP is generated during PC synthesis (see Fig. 3.2), so it will be plentiful at a time close to parturition. These regulatory aspects of acidic phospholipid formation have been fully discussed (Bleasdale et al., 1985; Possmayer, 1987).

\section{Remodeling of Newly Formed Phospholipids}

Alveolar surfactant is remarkable for the unusual molecular species distribution in its phospholipid classes, especially PC. The operation of the CDP-choline pathway (Fig. 3.2), however, results in a mixture of PCs that mainly reflect the fatty acid composition of the diacylglycerols formed by phosphatidate phosphohydrolase. Thus, in order to generate large amounts of DPPC, the fatty acid composition must be changed. There are two obvious ways to do this (Fig. 3.3). Either a phospholipase $A_{2}$ removes the

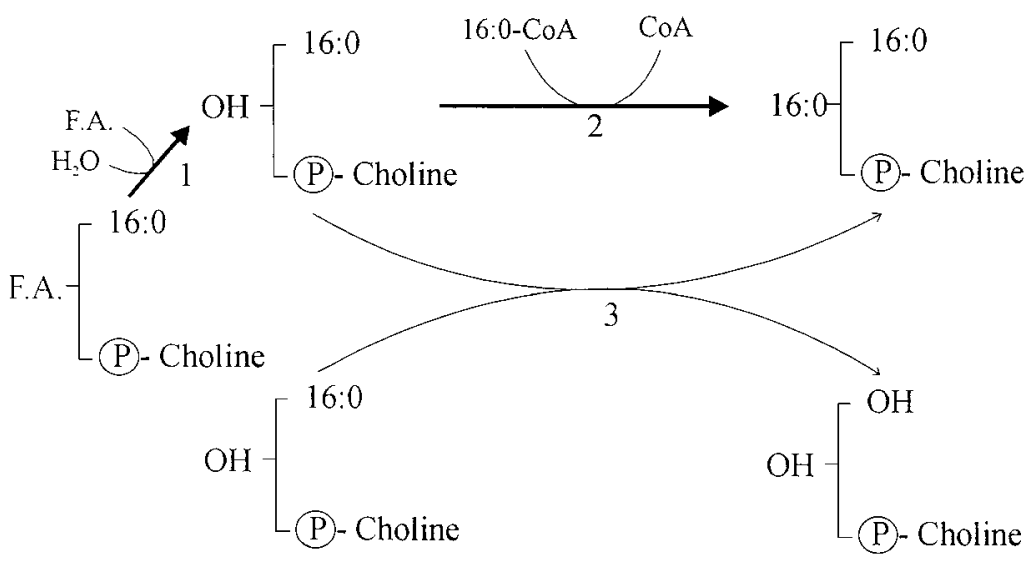

Figure 3.3. Possible pathways of remodeling to enrich phosphatidylcholine with palmitate (taken from Harwood (1987) with permission). 
(mainly unsaturated) fatty acid from the $s n-2$ position of glycerol and this is replaced with palmitate through the action of a monoacyl(lyso)PC acyltransferase, or interlipid transfer takes place. In the latter reaction, two molecules of monoacylPC react together with one providing the source of the palmitate. Experiments measuring in vitro enzyme activities, with cultured Type-II cells from the lung and by double labeling techniques with lung slices, suggest that the phospholipase $\mathrm{A}_{2}$ /acyltransferase route is the main pathway for remodeling (see Batenburg, 1984).

In addition to PC, the alveolar surfactant phosphatidylglycerol is also enriched in palmitate, so it is likely that a similar type of remodeling also applies to this component.

\section{Alveolar Surfactant Contains Special Proteins}

The isolation of a lipid-rich surfactant pellet from lung lavage yields a preparation that contains many proteins, most of which have been identified as serum-derived. Extraction of lipid from the pellet leaves behind a major nonserum protein referred to as surfactant protein A (SP-A). In humans, SP-A consists of a major charge train of 9-13 proteins (molecular masses $34-36 \mathrm{kDa}$ ) and a minor charge train of three proteins (molecular masses $28-30 \mathrm{kDa}$ ). The charge and size heterogeneity of SP-A varies among species and primarily reflects the addition of one or two asparagine-linked oligosaccharide chains to a species-specific backbone of about 230 residues (Weaver and Whitsett, 1991). In airways, SP-A exists in thiol-dependent and non-thioldependent oligomers of $0.5-1.6 \times 10^{6} \mathrm{kDa}$.

Unlike SP-A, two other surfactant proteins, SP-B and SP-C, are so hydrophobic that they remain in the lipid phase during standard extractions. SP-B is a protein of about $8 \mathrm{kDa}$ and forms thiol-dependent oligomers with dimers being the most common. SP$\mathrm{C}$ is a mixture of three peptides of 33-35 amino acid residues, which differ only in their $\mathrm{N}$-terminus (see e.g., Johansson et al., 1988). SP-C can aggregate in vitro to form non-thiol-dependent dimers.

A fourth surfactant-associated $43 \mathrm{kDa}$ hydrophilic protein, SP-D, has been found as a minor component in various alveolar surfactants; however, even though it shares some structural similarities to SP-A, it does not co-isolate with other surfactant components. It has been estimated that the concentration of SP-D in the rat lung is about $12 \%$ that of SP-A (Wright, 1997). No surface tension-lowering effect has been found, and SP-D is thought to have defense properties, as seen in other collectins (Johansson and Curstedt, 1997). Collectins are a family of collagenous carbohydrate binding proteins consisting of oligomers of trimeric subunits.

\section{The Different Structures of Surfactant-Associated Proteins}

The gene for SP-A has been sequenced from several species including humans (Weaver and Whitsett, 1991). It consists of five exons, with the coding sequence distributed among four. There may be more than one gene in humans and at least one pseudogene has been identified (Korfhagen et al., 1990). SP-A RNA encodes a protein of 248 amino acids (Fig. 3.4) in human, rat, and dog, and 247 amino acids in rabbit (see Weaver and Whitsett, 1991). The $\mathrm{N}$-terminal domain contains a signal peptide of 20 amino acids followed by a short (7-10 residue) sequence. A cysteine in this latter part allows the interprotein disulphide linkage that gives rise to a trimeric structure that forms the basis of the oligomeric (six trimers) native structure. The N-terminal domain then joins a collagenlike part of the protein (Fig. 3.4) with 23-24 Gly-X-Y repeats. Finally, there is a 148-residue noncollagenlike region that includes the carbohydrate-recognition 
SP-A

(proprotein)

SP-B

(proprotein)

SP-C

(proprotein)

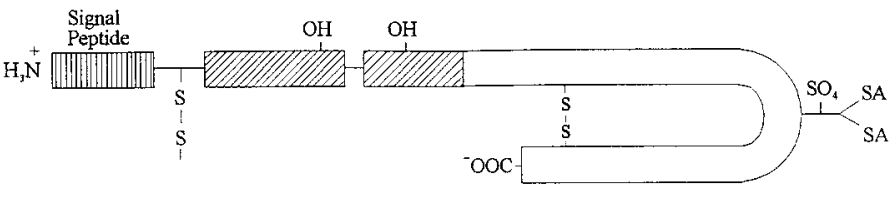

Active airway protein consisting of six trimers in its mature form

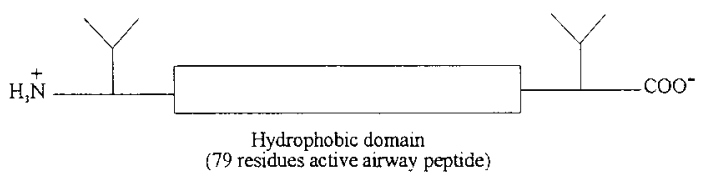

SP-D

(proprotein)

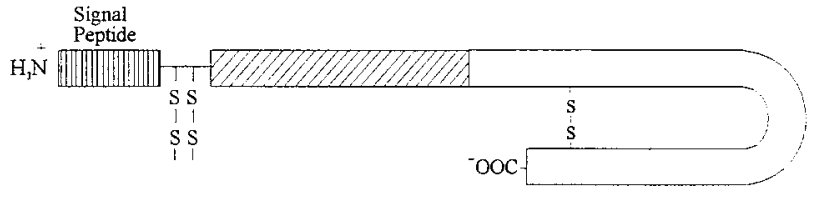

Active airway protein consisting

of four trimers in its mature form
$<=$ Asn-linked carbohydrate

$\mathrm{SA}=$ Sialic acid (according to Hawgood et al. (1985) up to $3 \mathrm{mols} /$ protein
Collagen-like domain of SP-A and SP-D

Carbohydrate-recognition domain of SP-A and SP-D

FIGURE 3.4. Simplified structures of the surfactant associated proteins (redrawn from information in Weaver and Whitsett (1991) with permission).

domain of 130 amino acids. There is a 24 amino acid "link" region located between the collagenlike and carbohydrate-recognition sequences that has been suggested to have a role in phospholipid binding (Ross et al., 1986). Other studies, however, have produced conflicting evidence for this proposed role (Whitsett and Weaver, 1991). 
For SP-B, restriction mapping of human genomic DNA is consistent with a single gene (Pilot-Matias et al., 1989). Sequences for SP-B cDNA from other species show changes resulting in only one or two amino acid substitutions. The SP-B RNA encodes a protein of 381 amino acids in humans. The latter consists of a signal peptide of 20-23 residues, a propeptide of about 176 residues, the mature 79-residue SP-B peptide, and a C-terminal peptide of 102 amino acids. The mature peptide contains three regions: an amphipathic helix, an extremely hydrophobic region, and an 11-residue sequence similar to the active sites of two proteinase inhibitors (Emrie et al., 1989).

The human SP-C gene is organized into six exons that encompass approximately 2$7 \mathrm{~kb}$ (Glasser et al., 1988). The SP-C RNA encodes a protein of 197 amino acids in human which, unlike most proteins to be secreted, does not contain a signal peptide. A mature 35-residue peptide is eventually produced that has an extremely hydrophobic region of 23 amino acids (residues $11-33$ ). This region is $43 \%$ valine and $35 \%$ leucine or isoleucine and is likely to form a rigid $\alpha$-helix capable of spanning a membrane bilayer. Residues 5 and 6, which are cysteines, appear to be palmitoylated (Curstedt et al., 1990), thus, further increasing the hydrophobicity of SP-C.

Surfactant protein D is a $43 \mathrm{kDa}, 355$ amino acid glycoprotein. Like SP-A, it belongs to the collectin family of proteins and has collagenous and noncollagenous domains of approximately equal size. SP-D has a short N-terminal region, a collagenlike domain with 59 Gly-X-Y repeats, a short "link" region, and a much longer carbohydrate recognition domain (CRD) than SP-A. Unlike SP-A, there is no kink interrupting its collagenlike domain (Johansson and Curstedt, 1997).

The processing and secretion of surfactant proteins is discussed by Weaver and Whitsett (1991).

\section{Possible Functions of Surfactant-Associated Proteins}

It has been found that surfactant proteins can directly affect the physical properties of surfactant lipids both in vitro and in vivo (Table 3.6). Purified SP-B, SP-C, or mixtures of the two markedly enhance the rate of formation of surface films. SP-A addition could further enhance the activity. When measured in a Wilhelmy balance or a pulsating bubble surfactometer, SP-B was particularly effective at reducing surface tensions of phospholipid mixtures (Weaver and Whitsett, 1991). In confirmation of these in vitro observations, preparations of SP-B, SP-C, and surfactant lipids increase lung compliance and preserve the morphological integrity of distal airways in lungs from premature rabbits or surfactant-deficient rat lungs (Sarin et al., 1990). In addition, antibodies against SP-B caused respiratory failure when given to mice (Fujita et al., 1988). In view of the preceding, it is encouraging that preparations of surfactant lipids containing mixtures of SP-B and SP-C have been successfully used in clinical trials to treat

TABLE 3.6. Possible functions of surfactant proteins.

\begin{tabular}{lccc}
\hline Function & SP-A & SP-B & SP-C \\
\hline - Contribute to surfactant properties of phospholipids & + & + & + \\
- Formation of tubular myelin & + & + & - \\
- Facilitate turnover of surfactant phospholipids & + & + & + \\
- Inhibition of pulmonary surfactant secretion & + & - & - \\
- Facilitate phagocytosis of opsonized particles & + & - & - \\
\hline
\end{tabular}

Source: From Weaver and Whitsett, 1991, with permission. 
premature infants suffering from respiratory distress syndrome and hyaline membrane disease. Treatment today is with exogenous surfactant replacement. This also is the case for a large number of pulmonary disturbances.

When surfactant is secreted it has been proposed that a tubular myelin structure is formed in the aqueous medium of the alveoli (see Fig. 3.5 later). This structure is thought to form spontaneously at the air-liquid interface from lamellar bodies when they are hydrated in the aqueous subphase (Johansson and Curstedt, 1997). Tubular myelin has also been proposed to be the precursor of the surface-active phospholipid monolayer, and both SP-A and SP-B are necessary to form tubular myelin from synthetic phospholipids (Suzuki et al., 1989). The precise role of tubular myelin in surfactant function, however, is still unclear (Weaver and Whitsett, 1991), even though it is a prominent structure in electron micrographs of lung tissue (Scarpelli and Mautone, 1984; Harwood and Richards, 1985).

After phospholipids have been secreted into the alveoli, they are gradually cleared, mainly by re-uptake into the Type-II epithelial cells. This process results in a half-life for DPPC of the order of about 12 hours for most animals. The re-uptake process appears to be stimulated by surfactant-associated proteins, especially SP-A. By contrast, this protein has also been shown to inhibit the secretion of surfactant phospholipids by Type-II cells in vitro. In addition, SP-A and SP-D have been suggested to have an important role in the immune defense system of the lung. Thus, SP-A increases phagocytosis of opsinized erythrocytes and bacteria by macrophages and monocytes (van Iwaarden et al., 1990). The receptor and SP-A domain involved in the receptor binding are probably different from those mediating the inhibition of surfactant secretion (see Weaver and Whitsett, 1991).

\section{Secretion and Turnover of Surfactant}

Various lines of evidence (e.g., microscopy or autoradiography) indicate that the various components of surfactant are packaged together in the lamellar bodies of the epithelial Type-II cells (Batenburg, 1984) before secretion by exocytosis into the alveoli. Confirmation of this came from experiments using radiolabeled precursors. It was found that the specific activities of PC, phosphatidylglycerol, phosphatidylinositol and cholesterol show identical changes in the alveolar lipids (Hass and Longmore, 1979) and that the appearance of DPPC and surfactant apoprotein parallel each other (King and Martin, 1980).

Lamellar bodies contain a very similar lipid composition to alveolar surfactant (see previous discussion), and isolated lamellar body fractions contain SP-A, SP-B, and SPC. Such fractions are capable of forming tubular myelin (in the presence of calcium) and reducing surface tension to less than $12 \mathrm{mN} / \mathrm{m}$, which suggests that the lamellar bodies contain the mature assembled phospholipid-protein complex (Farrell et al., 1990).

A general outline of secretion and turnover of surfactant, as well as the regulation of surfactant is shown in Fig. 3.5 and the regulation of surfactant secretion has been reviewed (Chander and Fisher, 1990). The control of surfactant secretion is not clearly understood and a large number of agents have been shown to have some activity in this regard. These include prostaglandins of the E series, cholinergic agents, and distension (stretch) of the alveolar epithelium (see Harwood and Richards, 1985). Most attention has been paid, however, to the role of $\beta$-adrenergic agents in the regulation of surfactant secretion (Walters, 1985). Epinephrine appears to be important at the time of birth in helping to establish normal breathing. It may also be involved in stress 


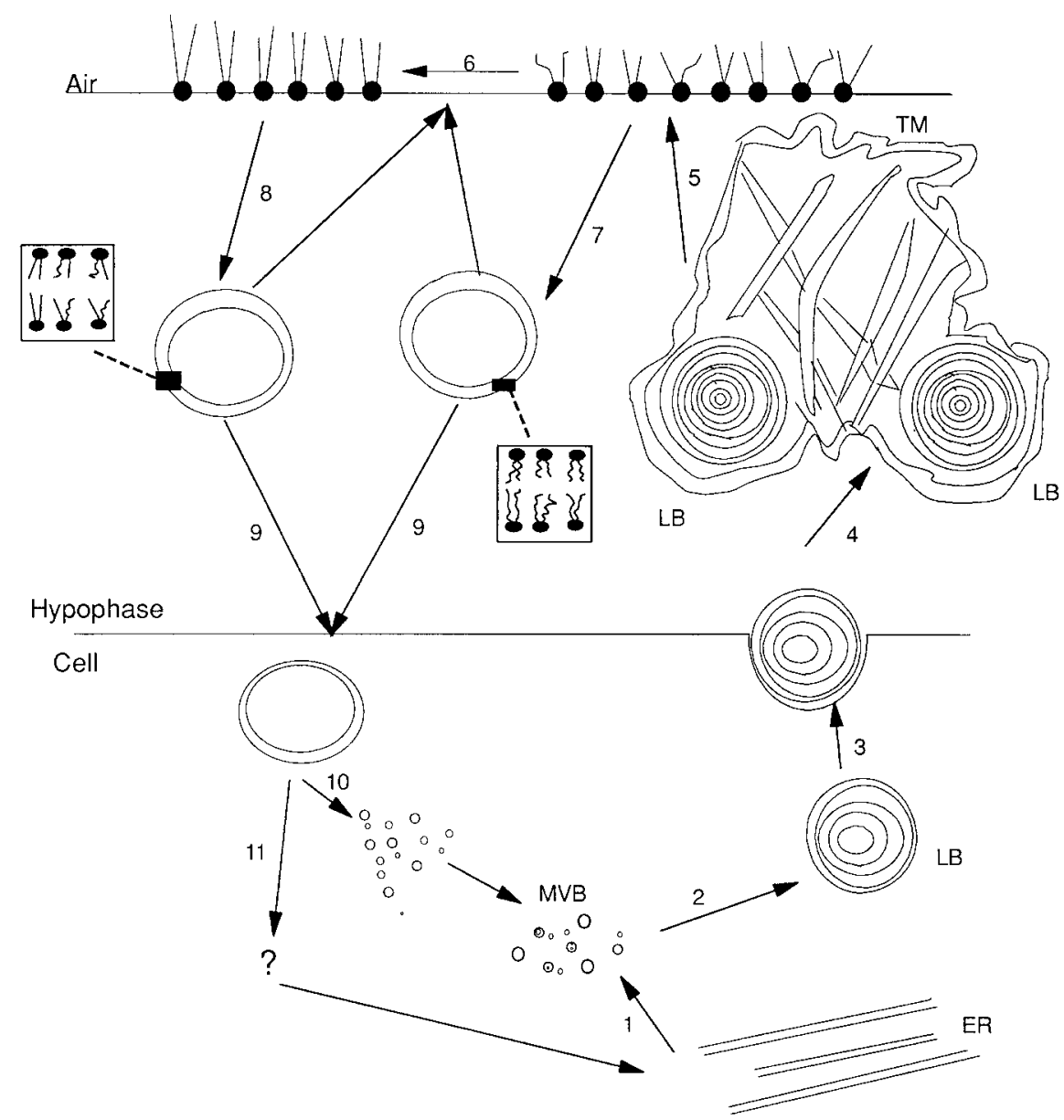

FIGURE 3.5. Diagrammatic illustration of the cycle of surfactant lipid secretion and re-utilization (taken from Harwood and Richards (1985) with permission).

reactions during which hyperventilation (and increased surfactant secretion) occur. It is unclear for the actual secretory process whether microtubules are involved or not (Harwood and Richards, 1985); however, experiments with cytochalasin B have shown that it will inhibit PC secretion in lung slices, presumably by disrupting the action of microfilaments. Such action has been shown to be concentrated around the lamellar bodies of Type-II cells and to become particularly prominent during surfactant secretion (see Walters, 1985).

Aspects of the metabolic and hormonal control of surfactant release have been covered by Bourbon (1991). In general, surfactant metabolism in the fetal lung differs from that in the adult lung. First, the kinetics of secretion are slower, second, the halflife is longer, and third, cycling is more efficient (Jobe and Igemani, 2001).

Although surfactant has long been known to have a relatively short half-life (King, 1974), there have been relatively few studies on its removal and/or catabolism. The possible ways in which surfactant can be removed or degraded are listed in Table 3.7. Although there is some evidence for each of these mechanisms, most results suggest that uptake and degradation/reutilization by Type-II cells is a major mechanism. With 
TABLE 3.7. Suggested ways for the breakdown or removal of alveolar surfactant.

- Clearance up the airways.

- Uptake by alveolar macrophages (followed by catabolism).

- Breakdown within the alveoli.

- Uptake by Type-I or Type-II epithelial cells (followed by degradation).

- Movement across the alveolar epithelia and clearance through the lymphatics.

- Uptake and reutilization by Type-II epithelial cells.

Source: From Harwood and Richards, 1985, with permission.

regard to the lipid components the data have been discussed by Jobe and Jacobs (1984) and by Wright and Clements (1987). Internalization of SP-A by alveolar macrophages can occur by a mannose-dependent mechanism associated with enhanced phagocytosis of opsonized targets (Tenner et al., 1989). In contrast, uptake of SP-A by Type-II cells occurs by a mannose-independent receptor-mediated process (see Weaver and Whitsett, 1991). The picture is less clear for the other surfactant-associated proteins. Both SP-B and SP-C appear to enhance the uptake of phospholipids by Type-II cells in a dose-dependent manner. SP-C itself appears to have a faster turnover rate than PC, and both Type-II cells and alveolar macrophages appear to participate in its turnover (i.e., with the former for recycling and the second for degradation). It is noteworthy in the latter connection, however, that both SP-B and SP-C are completely resistant to proteinase degradation in vitro (see Johansson et al., 1988).

\section{Respiratory Distress and Alveolar Surfactant}

Because alveolar surfactant is synthesized only in the late gestation stages, cases of premature birth often result in acute respiratory distress syndrome (RDS) or hyaline membrane disease (see Raivo, 1983). The incidence of RDS is related to the immaturity of the fetus and will almost always occur with babies born before 31 weeks. Below this age the chances of survival are closely related to gestation age. The major problem experienced by the RDS baby is a difficulty in lung expansion. Although surfactant deficiency is a primary cause of RDS, a number of ancillary problems complicate successful treatment by simple replacement therapy (Table 3.8; see Morley, 1985). There is no doubt, however, that both prophylactic and therapeutic ("rescue") administration of surfactant are safe and effective. It remains controversial whether prophylaxis or rescue is superior, except in premature infants of 26 weeks or less, in whom multidose prophylaxis is superior to multidose rescue (see Corbet, 1992).

TABLE 3.8. Compounding problems in respiratory distress syndrome.

- Babies have difficulty in clearing fluid from lungs after birth.

- Few alveoli are present in the immature lungs.

- Lung edema develops with pulmonary hypertension.

- Poor muscle development makes expansion of the stiff lungs even more difficult. If a deep breath is made, the immature ribs are so soft that the chest wall is drawn in, thus reducing the lung volume.

- Although some surfactant is present, it has less saturated PC and less phosphatidylglycerol than normal.

- Substantial amounts of serum protein leak onto the alveolar surfaces.

Source: From Harwood and Richards, 1985, with permission. 
A key fact for the obstetrician is to be able to predict, in advance, the risk of RDS. Because of biological variation, measurements of gestational age and fetal size, although useful, are unfortunately insufficient in themselves. Diagnosis of a high risk of RDS can influence the timing of elective preterm deliveries such that the incidence of RDS can be significantly reduced. However, amniocentesis (by which surfactant levels are assessed) is not without possible complications, and there are problems associated with some forms of treatment (e.g., glucocorticoids) that are used to accelerate lung maturation (Harwood and Richards, 1985). Some measurements of amniotic fluid which have been used to predict RDS are given in Table 3.9.

Two general methods have been used to treat RDS in infants. First, hormones have been utilized to hasten lung maturation and increase surfactant production. Second, replacement therapy with various artificial surfactants has been tried. The earlier work on hormones has been reviewed (Perelman et al., 1985; Harwood, 1987) and, because research has concentrated on replacement therapy with artificial surfactants, the latter topic will be emphasized here. There are useful reviews of this subject by Walti et al. (1991) and Giese (1999).

There have been more than 30 randomized controlled trials of the use of surfactant with more than 6000 babies having been enrolled in these studies. The results have been reviewed (Avery and Merritt, 1991; Morley, 1991) and the data subjected to metaanalysis (Hennes et al., 1991; Soll, 1991). There are considerable problems in comparing the results of individual trials mainly because of differences in the populations randomized, in exclusion criteria and in the outcomes assessed. Moreover, general differences relate to whether the surfactant used was natural or synthetic, and to whether the trial compares the prophylactic use or rescue use of surfactant (Colditz and Henderson-Smart, 1992). When outcomes were assessed, however, there appeared to be little significant difference for most criteria with the nature of the surfactant or its method of use. Mortality, pneumothorax, and intraventricular hemorrhage were all especially improved compared with untreated babies (see Colditz and HendersonSmart, 1992). To take a specific example, where Infasurf (a bovine-derived surfactant) was administered at $90 \mathrm{mg} /$ infant weighing less than $1 \mathrm{~kg}$ or $180 \mathrm{mg} /$ infant greater than $1 \mathrm{~kg}$, surfactant replacement therapy improved gas exchange in infants with RDS in addition to reducing pulmonary complications. Of 17 infants weighing 500-750g who were given surfactant replacement therapy, one developed respiratory distress and 7

TABLE 3.9. Some measurements with amniotic fluid that have been used to predict respiratory distress syndrome.

\begin{tabular}{ll}
\hline Measurement & \multicolumn{1}{c}{ Comments } \\
\hline PC/Sph ratio & $\begin{array}{l}\text { Significant number of false negatives. Ratio }>2 \text { assures lung } \\
\text { maturity. Charring methods on TLC need to be modified } \\
\text { for DPPC. }\end{array}$ \\
$\begin{array}{l}\text { Relative \% of PI and/or PG } \\
\text { Surfactant apoprotein (35 KDa) }\end{array}$ & $\begin{array}{l}\text { Probably will gain increasing popularity. Sensitive if linked } \\
\text { to ELISA assay. }\end{array}$ \\
$\begin{array}{l}\text { Bubble stability (shake test) } \\
\text { Fluorescence polarization } \\
\text { Enzyme assays }\end{array}$ & $\begin{array}{l}\text { Simple, low cost. Number of false negatives high. } \\
\text { High cost instrument but simple to use and reliable. } \\
\text { Phosphatidate phosphohydrolaze only useful constituent. }\end{array}$ \\
\hline
\end{tabular}

Source: From Harwood, 1987, with permission.

Abbreviations: $\mathrm{Sph}=$ sphingomyelin: $\mathrm{PG}=$ phosphatidylglycerol; PI = phosphatidylinositol; ELISA $=$ enzyme-linked immunosorbent assay. 
of the 17 died. In 10 unmatched controls in the same weight range, nine infants developed RDS and nine died (Ioli and Richardson, 1990).

Studies using prophylactic surfactant suggest that there may be benefit in administering more than one dose of surfactant (Kendig et al., 1989). It has been postulated that a good response after a subsequent dose may be seen because of effects of serum proteins leaking into the air spaces that could inhibit the activity of the first dose (Ikegami et al., 1986). The clearance rate of exogenous surfactant has been studied following multiple doses of an artificial surfactant, Exosurf (a mixture of DPPC with hexadecanol and tyloxapol). Turnover of the artificial surfactants appears to be similar for figures with other exogenous surfactants, including naturally derived materials (Ashton et al., 1992a). Hallman et al. (1986) had previously calculated a mean half-life of the phosphatidylglycerol component of exogenous human surfactant to be 30 hours. As a result of their studies, Ashton et al., (1992a) concluded that, after giving two doses of Exosurf, further doses might best be delayed by 2 days to get maximum benefit from the replacement therapy. Cost-benefit analyses show clearly that surfactant replacement saves both lives and money for the health services (Colditz and Henderson-Smart, 1992). Such considerations have been discussed fully by Maniscalco et al. (1989).

The general topic of replacement therapy in RDS was reviewed by Fujiwara (1984) and the connection between lack of surfactant lipids (especially DPPC) and respiratory distress clearly established. Nevertheless, further work to confirm original observations has continued, and the connection can now be made on a much firmer basis (Ashton et al., 1992b). Moreover, development of different mixtures for possible use as lung surfactants has continued with the use of phospholipid analogues (e.g., Turcotte et al., 1991). Because of the beneficial action of surfactant-associated proteins, such as SP-B (Yu and Possmayer, 1992) on surfactant dynamics, their inclusion may be beneficial in spite of the possibility of allergic responses (Strayer et al., 1986). Finally, the availability of data from large-scale trials, such as the 23 hospital multicenter trial on Exosurf (Stevenson et al., 1992), has given us a lot more data to demonstrate convincingly that surfactant replacement therapy is of real benefit to infants with RDS. A source of referencing work is Robertson and Taeusch (1995).

\section{Other Diseases That May Involve Surfactant}

Adult respiratory distress syndrome (ARDS) is a much more common complaint than RDS of the newborn. A conservative estimate counts about 150,000 cases per year in the United States alone, with an average mortality of 40\% (Lachmann and Danzmann, 1984). There are many functional and pathological similarities between ARDS and RDS of the newborn, including a lack of alveolar surfactant. In ARDS, however, surfactant deficiency is a complication of lung injury rather than being a primary etiologic factor, as it is in neonatal RDS. In addition, RDS can be caused by protein inactivation of surfactant functions as a result of pulmonary edema. Nevertheless, the deficiency can be compensated for by the administration of exogenous surfactant (Lachmann and Danzmann, 1984). Such a course of action is increasingly recommended (e.g., Fuhrman, 1990; Giese, 1999).

The relative amounts of PC and PG have been shown to decrease in ARDS patients (Hallman et al., 1982, Pison et al., 1990). This decrease was more pronounced with an increasing severity of disease, which suggests that Type-II cell metabolic functions are altered in ARDS. It has also been demonstrated that SP-A and SP-B are decreased within ARDS patients compared to normal controls (Gregory et al., 1991). Evidence is increasing that this may be caused by cytokines such as TNF (Hallman et al., 2001). 
TABLE 3.10. Changes in surfactant induced by pharmacological agents or diseases.

\begin{tabular}{ll}
\hline Agent/disease & \multicolumn{1}{c}{ Surfactant change } \\
\hline Respiratory distress syndrome & Levels severely depressed \\
Adult RDS & Severe reduction \\
Alveolar (lipo)proteinosis & Levels increased \\
Quartz dust & Levels increased up to 50 times \\
Asbestos dust & Levels increased up to 20 times \\
Glass powder & Levels unchanged or slightly decreased \\
Chlorphentermine & Accumulation* \\
Imipramine & Accumulation* \\
Amitryptamine & Accumulation* \\
Chlorpromazine & Accumulation* \\
Oxygen toxicity & Decreased surfactant \\
Ozone & Decreased phosphatidylcholine synthesis in \\
& Type-II cells \\
Nitrogen dioxide & Transient increase in surfactant \\
Phosgene & Initial decrease in surfactant \\
Paraquat & Large decrease in surfactant \\
3-Methylindole & Accumulation \\
Peritonitis & Decreased or altered surfactant \\
Acute pancreatitis & Decreased surfactant \\
Diabetes & Main implication for babies born to diabetic \\
& mothers \\
Bleomycin-used in cancer therapy & Increased surfactant \\
Radiation & Decreased or abnormal surfactant \\
\hline
\end{tabular}

Source: From Harwood and Richards, 1985, with permission.

* Accumulation of surfactant only marked for instilled drugs. Normal clinical doses of, for example, imipramine have little effect.

Sudden infant death syndrome (SIDS) is the most common cause of death in infancy: It affects about one baby in every 500 dying between 1 week and 2 years in the United Kingdom (Morley et al., 1982). It has been found that surfactant from SIDS babies contained significantly less phospholipid and DPPC and relatively more phosphatidylglycerol than did that of babies dying from other causes (Morley et al., 1982). These results have been confirmed, but it is not yet clear whether surfactant deficiency and abnormality is a primary or secondary phenomenon in SIDS (James et al., 1990).

Surfactant deficiency is also believed to have a role in respiratory syncytical virus-associated bronchiolitis (Dargaville et al., 1995), where patients display ARDSlike symptoms. The virus attacks the surfactant-producing epithelial cells of the lung, which could then affect synthesis of surfactant material (Panitch et al., 1993). Decreased SP-A, PC, and PG have been observed in these patients (Dargaville et al., 1996, Skelton et al., 1999).

In addition to the preceding, there are a wide range of pharmacological agents or diseases that have been shown to affect surfactant quality or quantity (see Harwood and Richards, 1985). These are listed in Table 3.10. Thus, there are many areas of interest in surfactant metabolism and function, and even though our information on this unique lipoprotein mixture has increased considerably over the last 20 years, it seems 
certain that the subject of alveolar surfactant biochemistry will continue to be of major importance in medicine in the future.

\section{References}

Ashton, M.R., Postle, A.D., Hall, M.A., Austin, N.C., Smith, D.E., and Normand, I.C.S. (1992a) Turnover of exogenous artificial surfactant. Arch. Dis. Child. 67, 383-387.

Ashton, M.R., Postle, A.D., Hall, M.A., Smith, S.L., Kelly, F.J., and Normand, I.C.S. (1992b) Phosphatidylcholine composition of endotracheal tube aspirates of neonates and subsequent respiratory disease. Arch. Dis. Child. 67, 378-382.

Avery, M.E., and Merrit, T.A. (1991) Surfactant replacement therapy. N. Engl. J. Med. 324, 910-912.

BAL Co-operative Group Steering Committee (1990) Am. Rev. Resp. Dis. 141, S169-S202.

Ballard, P.L. (1989) Hormonal-regulation of pulmonary surfactant. Endocrine Rev. 10, 165181.

Bangham, A.D. (1991) Pattles's bubbles and Von Neergaard's lung. Med. Sci. Res. 19, 795-799.

Batenburg, J.J. (1984) Biosynthesis and secretion of pulmonary surfactant. In: Pulmonary surfactant, Robertson, B., van Golde, L.M.G., and Batenburg, J.J. (eds.) Elsevier, Amsterdam.

Batenburg, J.J., and Hallman, M. (1990) In: Pulmonary physiology: fetus, newborn, child, and adolescent, Scarpelli, E.M. (ed.) pp. 106-139. Lea and Febiger, Philadelphia.

Bleasdale, J.E., Maberry, M.C., and Quirk, J.G. (1982) Myo-inositol homeostasis in foetal rabbit lung. Biochem. J. 206, 43-52.

Bleasdale, J.E., and Johnston, J.M. (1985) In: Pulmonary development: transition from intrauterine to extraterrestrial life, Nelson, G.H. (ed.) pp. 47-73. Marcel Dekker, New York.

Bourbon, J.R., Francoual, J., Magny, J.F., Lindenbaum, A., Leluc, R., and Dehan, M. (1990) Changes in phospholipid composition of tracheal aspirates from newborns with hyaline membrane disease or transient tachypnoea. Clin. Chim. Acta 189, 87-91.

Bourbon, J.R. (1991) Nature, function, and biosynthesis of surfactant lipids. In: Pulmonary surfactant: biochemical, function, regulatory, and clinical concepts, Bourbon, J.R. (ed.) CRC Press, Boca Raton.

Chander, A., and Fisher, A.B. (1990) Regulation of lung surfactant secretion. Am. J. Physiol. 258, L241-253.

Colditz, P.B., and Henderson-Smart, D.J. (1992) Surfactant replacement therapy. J. Pediatr. Child Health 28, 210-216.

Corbet, A., and Long, W. (1992) Symposium on synthetic surfactant: introduction. J. Pediatr. 120, S1-S50.

Curstedt, T., Johansson, J., Persson, P., Eklund, A., Robertson, B., Lowenadler, B., and Jornvall, H. (1990) Hydrophobic surfactant-associated polypeptides: SP-C is a lipopeptide with two palmitoylated cysteine residues, whereas SP-B lacks covalently linked fatty acyl groups. Proc. Natl. Acad. Sci. U.S.A. 87, 2985-2989.

Dargaville, P.A., McDougall, P.N., and South, M. (1995) Surfactant abnormalities in severe viral bronchiolitis. Appl. Cardiopulm. Pathophysiol. 5 (suppl. 3), 20.

Dargaville, P.A., South, M., and McDougall, P.N. (1996) Surfactant abnormalities in infants with severe viral bronchiolitis. Arch. Dis. Childhood 72, 133-136.

Enhorning, G. (1977) Pulsatile bubble technique for evaluating pulmonary surfactant. J. Appl. Physiol. 43, 198-203.

Emrie, P.A., Shannon, J.M., Mason, R.J., and Fisher, J.H. (1989) cDNA and deduced amino acid sequence for the rat hydrophobic pulmonary surfactant-associated protein, SP-B. Biochim. Biophys. Acta 994, 215-221.

Farrel, P.M., Bourbon, J.R., Notter, R.H., Martin, L., Nogee, L.M., and Whitsett, J.A. (1990) Relationships among surfactant fraction lipids, proteins, and biophysical properties in the developing rat lung. Biochim. Biophys. Acta 1044, 84-90.

Feldman, D.A., Kovac, C.R., Dranginis, P.L., and Weinhold, P.A. (1978) The role of phosphatidylglycerol in the activation of CTP: phosphocholine cytidylyltransferase from rat lung. J. Biol. Chem. 253, 4980-4986. 
Feldman, D.A., Rounsifer, M.A., Charles, L., and Weinhold, P.A. (1990) CTP: phosphocholine cytidylyltransferase in rat lung: relationship between cytosolic and membrane forms. Biochim. Biophys. Acta 1045, 49-57.

Fujita, Y., Kogishi, K., and Suzuki, Y. (1988) Pulmonary damage induced in mice by a monoclonalantibody to proteins associated with pig pulmonary surfactant. Exp. Lung Res. 14, 247-260.

Fujiwara, T. (1984) In: Pulmonary surfactant, Robertson, B., van Golde, L.M.G., and Batenburg, J.J. (eds.) pp. 479-503. Elsevier, Amsterdam.

Fuhrman, B.P. (1990) Surfactant therapy. Crit. Care Med. 18, 682-683.

Gaines, G.L. (1966) Insoluble monolayers at liquid-gas interfaces. John Wiley and Sons New York.

Glasser, S.W., Korfhagen, T.R., Perme, C.M., Pilot-Matias, T.J., Kister, S.E., and Whitsett, J.A. (1988) Two SP-C genes encoding human pulmonary surfactant proteolipid. J. Biol. Chem. 263, 10326-10331.

Goerke, J., and Gonzales, J. (1981) Temperature dependence of dipalmitoyl phosphatidylcholine monolayer stability. J. Appl. Physiol. 51, 1108-1114.

Gregory, T.J., Longmore, W.J., Moxley, M.A., Whitsett, J.A., Reed, C.R., Fowler, A.A. et al. (1991) Surfactant chemical composition and biophysical activity in acute respiratory distress syndrome. J. Clin. Invest. 88, 1976-1981.

Griese, M. (1999) Pulmonary surfactant in health and human lung disease: state of the art. Eur. Resp. J. 13, 1455-1476.

Haagsman, H.P., and Diemel, R.V. (2001) Surfactant-associated proteins: functions and structural variation. Comp. Biochem. Physiol. Part A. 129, 91-108.

Hallman, M., and Epstein, B. (1982) Role of myo-inositol in the synthesis of phosphatidylglycerol and phosphatidylinositol in the lung. Biochem. Biophys. Res. Commun. 92, 1151-1159.

Hallman, M., Glumoff, V., and Ramet, M. (2001) Surfactant in respiratory distress syndrome and lung injury. Comp. Bio. Physiol. Part A. 129, 287-294.

Hallman, M., Slivka, S., Wozniak, P., and Sils, J. (1986) Perinatal development of myo-inositol uptake into lung cells: surfactant phosphatidylglycerol and phosphatidylinositol synthesis in the rabbit. Pediatr. Res. 20, 179-185.

Hallman, M., Spragg, R., Harrell, J.H., Moser, K.M., and Gluck, L. (1982) Evidence of lung surfactant abnormality in respiratory-failure - study of bronchoalveolar lavage phospholipids, surface-activity, phospholipase-activity, and plasma myoinositol. J. Clin. Invest. 70, 673-683.

Harwood, J.L., and Richards, R.J. (1985) Lung surfactant. Mol. Aspects Med. 8, 423-514.

Harwood, J.L. (1987) Lung surfactant. Prog. Lipid Res. 26, 211-256.

Hass, M.A., and Longmore, W.J. (1979) Surfactant cholesterol metabolism of the isolated perfused rat lung. Biochim. Biophys. Acta 573, 166-174.

Hawco, M.W., Davis, P.J., and Keough, K.M.W. (1981) Lipid fluidity in lung surfactant: monolayers of saturated and unsaturated lecithins. J. Appl. Physiol. 51, 509-515.

Hawgood, S., Efrati, H., Schilling, J., and Benson, B.J. (1985) Chemical characterisation of lung surfactant apoproteins: amino acid composition, N-terminal sequence, and enzymic digestion. Biochem. Soc. Trans. 13, 1092-1096.

Hennes, H.M., Lee, M.B., Rimm, A.A., and Shapiro, D.L. (1991) Surfactant replacement therapy in respiratory distress syndrome: meta-analysis of clinical trials of single-dose surfactant extracts. Am. J. Dis. Child. 145, 102-104.

Ikegami, M., Jobe, A., and Berry, D.A. (1986) A protein that inhibits surfactant in respiratory distress syndrome. Biol. Neonate 50,121-129.

Ioli, J.G., and Richardson, M.J. (1990) Giving surfactant to premature infants. Am. J. Nurs. 90, $59-60$.

James, D., Berry, P.J., Fleming, P., and Hathaway, M. (1990) Surfactant abnormality and the sudden infant death syndrome-a primary or secondary phenomenon. Arch. Dis. Child. 65, 774-778.

Jobe, A.H., and Ikegami, M. (2001) Biology of surfactant. Clin. Perinat. 28, 655-669.

Jobe, A.H., and Jacobs, H.C. (1984) Catabolism of pulmonary surfactant. In: Pulmonary surfactant, Robertson, B., van Golde, L.M.G., and Batenburg, J.J. (eds.) pp. 271-293. Elsevier, Amsterdam.

Johansson, J., Curstedt, T., Robertson, B., and Jornvall, H. (1988) Size and structure of the hydrophobic low molecular weight surfactant-associated polypeptide. Biochemistry 27, 3544-3547. 
Johansson, J., and Curstedt, T. (1997) Molecular structures and interactions of pulmonary surfactant components. Eur. J. Biochem. 244, 675-693.

Johansson, J., Jornvall, H., Eklund, A., Christensen, N., Robertson, B., and Curstedt, T. (1988) Hydrophobic $3.7 \mathrm{KDa}$ surfactant polypeptides structural characterisation of the human and bovine forms. FEBS Lett. 232, 61-64.

Kalmar, G.B., Kay, R.J., La Chance, A.C., and Cornell, R.B. (1994) Primary structure and expression of a human CTP-phosphocholine cytidylyltransferase. Biochim. Biophys. Acta 1219, 328-334.

Kendig, J.W., Notter, R.H., and Maniscalco, W.M. (1989) Clinical experience with calf lung surfactant. In: Surfactant therapy, Shapiro, D.L., Notter, R.H. (eds.) pp. 257-271. Alan Liss, New York.

King, R.J. (1974) The surfactant system of the lung. Fed. Proc. Fed. Am. Soc. Exp. Biol. 33, 2238-2247.

King, R.J., and Clements, J.A. (1972) Surface active material from dog lung. II. Composition and physiological correlations. Am. J. Physiol. 223, 715-726.

King R.J., and Martin, H. (1980) Intracellular metabolism of the apoproteins of pulmonary surfactant in rat lung. J. Appl. Physiol. 48, 812-820.

Korfhagen, T.R., Glasser, S.W., Bruno, M.D., McMahan, M.J., Clark, J.C., and Whitsett, J.A. (1990) Isolation and analysis of the murine surfactant protein-A genomic locus. Am. Rev. Respir. Dis. $142,4,2$, A696.

Lachmann, B., and Danzmann, E. (1984) In: Pulmonary surfactant, Robertson, B., van Golde, L.M.G., and Batenburg, J.J. (eds.) pp. 505-548. Elsevier, Amsterdam.

Maniscalco, W.M., Kendig, J.W., and Shapiro, D.L. (1989) Surfactant replacement therapy: impact on hospital charges for premature infants with respiratory distress syndrome. Pediatrics $83,1-6$.

Morley, C.J. (1985) The role of $\beta$-adrenergic agents in the control of surfactant secretion. Biochem. Soc. Trans. 13, 1091-1092.

Morley, C.J. (1991) Surfactant treatment for premature babies: a review of clinical trials. Arch. Dis. Child. 66, 445-450.

Morley, C.J., Hill, C.M., Brown, B.D., Barson, A.J., and Davis, J.A. (1982) Surfactant abnormalities in babies dying from sudden infant death syndrome. Lancet, 1320-1322.

Perelman, R.H., Farrell, P.M., Engle, M.J., and Kemnitz, J.W. (1985) Developmental aspects of lung lipids. Ann. Rev. Physiol. 47, 803-822.

Pilot-Matias, T.J., Kister, S.E., Fox, J.L., Kroop, K., Glasser, S.W., and Whitsett, J.A. (1989) Structure and organisation of the gene encoding human pulmonary surfactant proteolipid SP-B. DNA 8, 75-86.

Pison, U., Obertacke, U., Brand, M., Seeger, W., Joka, T., Bruch, J., and Schmitneuerburg, K.P. (1990) Altered pulmonary surfactant in uncomplicated and septicemia-complicated courses of acute respiratory failure. J. Trauma Injury Infection Crit. Care 30, 191-226.

Possmayer, F. (1987) In: Phosphatidate phosphohydrolase, Brindley, D.N. (ed.) CRC Press, Boca Raton.

Post, M. (1987) Maternal administration of dexamethasone stimulates choline-phosphate cytidylyltransferase in fetal type II cells. Biochem. J. 241, 291-296.

Post, M., and van Golde, L.M.G. (1988) Metabolic and developmental aspects of the pulmonary surfactant system. Biochim. Biophys. Acta 947, 249-286.

Raivo, K. (ed.) (1983) Respiratory distress syndrome. Academic Press, New York.

Robertson, B., and Taeusch, H.W. (ed.) (1995) Surfactant therapy for lung disease. Marcel Dekker, New York.

Ross, G.F., Meuth, J., and Ohning, B. (1986) Purification of canine surfactant-associated glycoproteins A. Identification of a collagenase-resistant domain. Biochim. Biophys. Acta 870, 267-278.

Sarin, V.K., Gupta, S., Leung, T.K., Taylor, V.E., Ohning, B.L., Whitsett, J.A., and Fox, J.L. (1990) Biophysical and biological activity of a synthetic $8.7 \mathrm{KDa}$ hydrophobic pulmonary surfactant protein SP-B. Proc. Natl. Acad. Sci. U.S.A. 87, 2633-2637.

Scarpelli, E.M., and Mautone, A.J. (1984) In: Pulmonary surfactant, Robertson, B., van Golde, L.M.G., and Batenburg, J.J. (eds.) pp. 119-170. Elsevier, Amsterdam. 
Skelton, R., Holland, P., Darowski, M., Cheteuh, P.A., Morgan, L.W., and Harwood, J.L. (1999) Abnormal surfactant composition and activity in severe bronchiolitis. Acta Paediatrica (in press).

Soll, R.F. (1991) Surfactant treatment of RDS. In: Chalmers 1, ed., Oxford Database of Perinatal Trials, Version 1.2, Disk issue 5.

Stern, W., Kovac, C., and Weinhold, P.A. (1976) Activity and properties of CTP: choline phosphate cytidylyltransferase in adult and fetal rat lung. Biochim. Biophys. Acta 441, 280-293.

Stevenson, D., Walther, F., Long, W. et al. (1992) Controlled trial of a single dose of synthetic surfactant at birth in infants weighing 500-600 grams. J. Pediatr. 120, S3-S12.

Strayer, D.S., Merritt, T.A., Lwebuga-Mukassa, J., and Hallman, M. (1986) Surfactant-antisurfactant immune complexes in infants with respiratory distress syndrome. Am. J. Pathol. 122, 353-362.

Suzuki, Y., Fujita, Y., and Kogishi, K. (1989) Reconstitution of tubular myelin from synthetic lipids and proteins associated with pig pulmonary surfactant. Am. Rev. Respir. Dis. 140, 75-81.

Tenner, A.J., Robinson, S.L., Borchelt, J., and Wright, J.R. (1989) Human pulmonary surfactant protein (SP-A), a protein structurally homologous to CIQ, can enhance FCR-mediated and CRI-mediated phagocytosis. J. Biol. Chem. 264, 13923-13928.

Turcotte, J.G., Lin, W.H., Pivarnik, P.E., Sacco, A.M., Shirali, S.S., Bermel, M.M., Lu, Z., and Notter, R.H. (1991) Chemical synthesis and surface activity of lung surfactant phospholipid analogs. II. Racemic N-substituted diether phosphonolipid. Biochim. Biophys. Acta 1084, 1-12.

van Golde, L.M.G., Batenburg, J.J., and Robertson, B. (1988) The pulmonary surfactant systembiochemical aspects and functional significances. Physiol. Rev. 68, 374-455.

van Iwaarden, F., Welmers, B., Verhoef, J., Haagsman, H.P., and van Golde, L.M.G. (1990) Pulmonary surfactant protein-A enhances the host-defence mechanism of rat alveolar macrophages. Am. J. Respir. Cell. Mol. Biol. 2, 91-98.

Walters, D.V. (1985) The role of $\beta$-adrenergic agents in the control of surfactant secretion. Biochem. Soc. Trans. 13, 1089-1090.

Walti, H., Couchard, M., and Relier, J-P. (1991) In: Pulmonary surfactant: biochemical function, regulatory, and clinical aspects, Bourbon, J.R. (ed.) pp. 385-429. CRC Press, Boca Raton.

Weaver, T.E., and Whitsett, J.A. (1991) Function and regulation of expression of pulmonary surfactant-associated proteins. Biochem. J. 273, 249-264.

Whitsett, J.A., Hull, W., Ross, G., and Weaver, T. (1985) Characteristics of human surfactantassociated glycoprotein-A. Pediatr. Res. 19, 501-508.

Wright, J.R. (1997) Immunomodulatory functions of surfactant. Physiol. Rev. 77, 931-962.

Wright, J.R., and Clements, J.A. (1987) Metabolism and turnover of lung surfactant. Am. Rev. Respir. Dis. 135, 426-444.

Yu, S-H., and Possmayer, F. (1992) Effect of pulmonary surfactant protein B(SP-B) and calcium on phospholipid adsorption and squeeze-out of phosphatidylglycerol from binary phospholipid monolayers containing dipalmitoylphosphatidylcholine. Biochim. Biophys. Acta 126, 26-34.

\section{Recommended Readings}

Griese, M. (1999) Pulmonary surfactant in health and human lung disease: state of the art. Eur. Res. J. 13, 1455-1476.

Hills, B.A. (1999) An alternative view of the role(s) of surfactant and the alveolar model. J. Appl. Physiol. 87, 1567-1583.

Notter, R.H. (2000) Lung surfactants: basic science and clinical applications. Marcel Dekker, New York.

Scarpelli, E.M. (1998) The alveolar surface network: a new anatomy and its physiological significance. Anat. Record 251, 491-527. 